\title{
Open Building as a condition for industrial construction
}

\author{
N. John Habraken
}

\author{
Prof.of Architecture,Emeritus, MIT,john@habraken.com
}

\begin{abstract}
Open Building advocates the direct relation between industrial manufacturing and the user / inhabitant. To make the industry-consumer relationship possible, base-buildings must offer space available for user controlled fit-out. To date, a fairly large number of experimental projects have been executed on a global scale. They demonstrate the potential of the approach. A re-distribution of design control involving all professional parties in the building industry is implied. To open this market, economic, legal, political, and bureaucratic policies must adapt.
\end{abstract}

KEYWORDS: Housing, systematization, industrialization, user control, design distribution.

\section{INTRODUCTION}

Open Building implies a two-fisted strategy. In a social perspective it seeks to respond to user's preferences by offering flexibility needed for adaptation of individual units over time. In a technical perspective it seeks ways of building where sub-systems can be installed or changed or removed with a minimum of interface problems. These two goals clearly complement one another and cover an wide spectrum of expertise. Open Building is supported by designers, managers, builders, and manufacturers, who each see advantages in it for their own professional role. In the sixties, research at the SAR ( Foundation for Architects Research) in the Netherlands proposed the separation of a 'base-building' and its interior 'fit-out' - the so called 'support / infill' approach in pursuit of the same goals. True to its name, SAR focused on methods for design in open projects. The present Open Building network seeks a broader interpretation of the same principles.

Open Building as an organization is now formalized as CIB workgroup W104 which has a global membership and meets every year in another part of the world. To illustrate what the Open Building approach stands for, I will show some examples of what could be termed Open Building projects. Next we will consider more specifically how Open Building provides a context for the development and improvement of Industrial Construction.

\section{EXAMPLES AND OBSERVATIONS}

\subsection{NEXT21 project, Osaka, Japan}

An experimental building, known as NEXT21, was completed for Osaka Gas Company in 1994 in the city of Osaka. Prof. Yositika Utida, Japan's premier authority on industrial residential construction, was asked to design the apartment building of the future. Not surprisingly, it contains the most advanced technology for the use of energy. Natural gas is chemically decomposed following principles first implemented for space craft. Solar panels are found on the building's roof garden. Waste from inhabitation is entirely processed for re-cycling.

\subsubsection{Open Building Principles}

Utida decided NEXT21 should also follow Open Building principles and assembled a team of designers to do just that. Prof. Tatsumi and his younger colleague Takada in Kyoto University already had done several open building projects in the Osaka region. The office of Shu-Ko-Sha led by architect Chikazumi joined to do actual design work and Prof. Fukao of Tokyo Univerisity developed principles of modular coordination. This team, accompanied by experts representing the client, made a study visit to the Netherlands to see already implemented Open Building projects. [NEXT21]. 


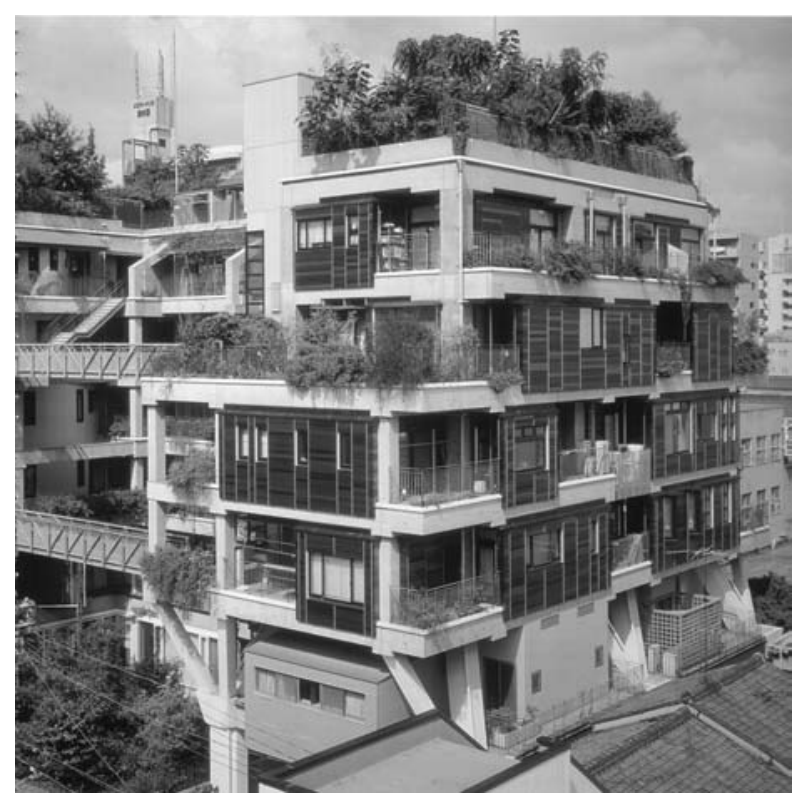

Figure 1. NEXT21 project, partial view

\subsubsection{Three Dimensional Urban Design}

The NEXT21 building demonstrates a clear distinction between 'base-building' and 'fit-out' following the SAR definition: the base-building serves as a collective facility, and the fit-out is different for each unit. The NEXT21 base building includes parking, pedestrian circulation both horizontally and vertically, and two public gardens, one on ground level and one on the roof. Utida declared the base building to be 'three dimensional urban design'. Drawing the full consequences of this analogy, he invited thirteen different architects to design the individual units, in the way individual architects design buildings in an urban scheme done previously by another firm.

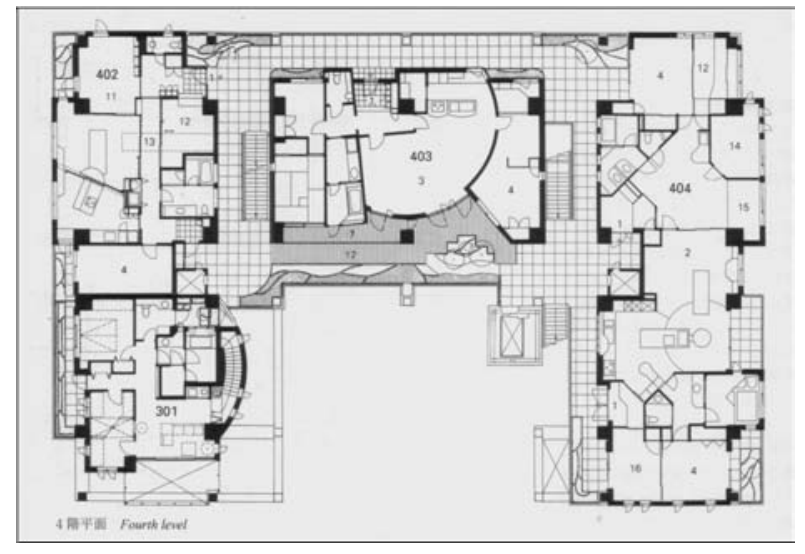

Figure 2. NEXT21 project, sample floor plan

\subsubsection{State of the Art Technology}

The Utida team applied available sub-systems to fit out individual units. But it set down clear rules for separation of base building and fit-out to enable the new distribution of design responsibilities.

To facilitate this separation the base building offers not only empty spaces for inhabitation, but also a two feet double floor that can be reached by detachable floor panels and contains the infrastructure of utilities like gas, water, and energy as well as waste drainage. Fit-out can also use the double floor space to connect to these utilities and extend them throughout the individual dwelling. Like in urban design, the spatial hierarchy is matched by a hierarchy in the utility systems.

\subsubsection{Façade System}

The NEXT21 façade system was newly invented and considered part of the fit-out system. Providing aluminum panels and a variety of windows and doors, facades can be installed and taken apart without need for outside scaffolding, thus enabling easy adaptation later on.

\subsection{Molenvliet project, Netherlands}

The project in which Utida's team was most interested when visiting Holland was in the town of Papendrecht, near Rotterdam. Designed by architect Frans van der Werf, the Molenvliet Project is considered the first true implementation of the SAR approach. Built in the early seventies the project had to follow the strict rules for public housing of the time. But by making the basebuilding / fit-out separation very clear in both technical and architectural terms, van der Werf successfully enabled the users to design their own. Here too, the technology was state of the art.

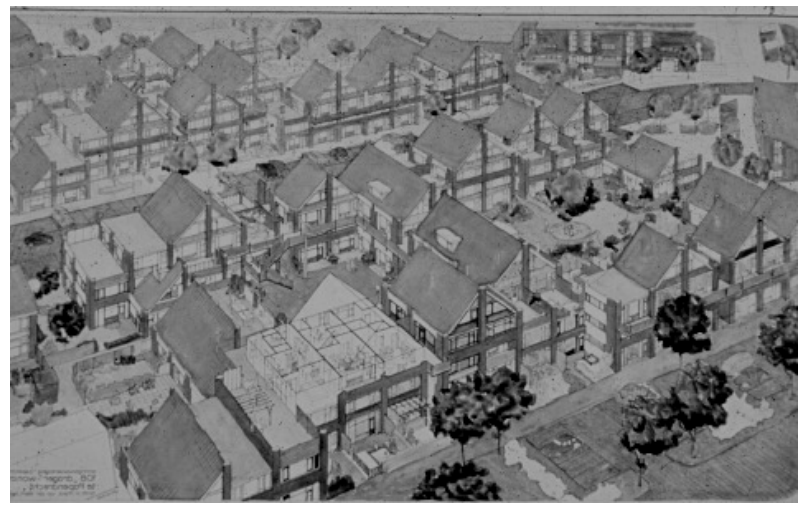

Figure 3. Molenvliet project, birds eye view 


\subsubsection{An Urban Fabric.}

The Molenvliet project also can be called three dimensional urban design. We do not see separate buildings but a continuous 'urban framework' which forms courtyards interconnected by pedestrian alleys and accessible from the public street where cars are parked. Some courtyards are public and give direct access to the units on the ground floor while open public galleries lead to units on the second floor. Other courtyards contain garden space: both individual gardens for ground floor units, as well as collective gardens.
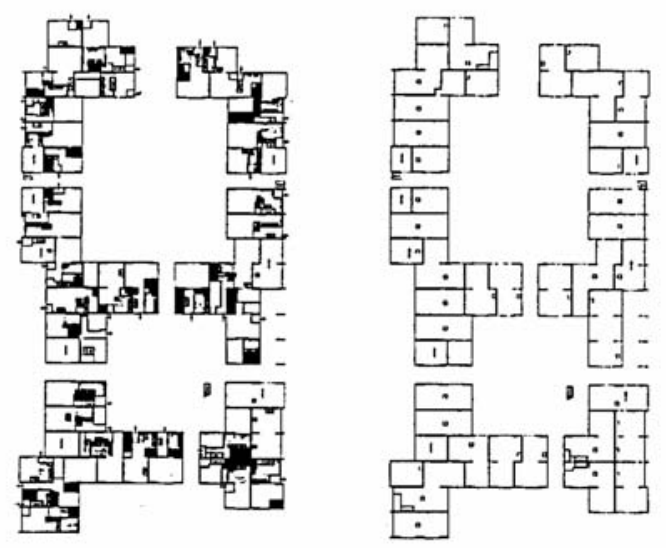

Figure 4. part of the Molenvliet project, right: territorial subdivision, left: individual floor plans.

\subsubsection{Users Designing}

Van der Werf allowed only two interviews with each of the user households to help them with their design. This proved sufficient. Because the units were for rent, cooperation of the owner of the estate, a non-profit corporation, was essential. Still, today, the management works in close cooperation with the users, and helps them adapt their unit's interior layout and equipment. [v.d.Werf]

\subsection{A world wide trend.}

Architect Frans van der Werf has recently completed his seventh Open Building residential project and is busy with the next. His Open Building projects are still much advanced in today's practice, but no longer experimental. Nor is he the only one working this way in the Netherlands. The NEXT21 project has triggered a spate of Open Building Initiatives in Japan, most of which are supported by the government. Some are truly experimental, others already commercially viable. Finland also has government supported policies promoting Open Building in practice and in research. The CIB workgroup W104 on Open Building has members of these three countries as well as from the United States, Mexico, Canada, Taiwan, China, Hong Kong, Singapore, Germany, and other countries.

A world wide overview of Residential Open Building projects up to 1999 can be found in a book by Kendall and Teicher [Kendall] They list 131 projects, some twenty of which are shown in some detail. The book gives an overview of technical, economical, and management issues related to this approach.

\subsection{Commercial Open Building}

The practice of Open Building is already quite familiar in commercial construction. Office buildings are routinely built as base buildings in which entire floors are leased to the occupant and fitted out by dedicated fit-out contracting firms according to the design of dedicated fit-out designers. The shopping mall shows this distinction as well. The mall's architect creates the public space in all its details, but leaves empty the retail floor space to be fitted out by specialized contractors serving occupant controlled design.

\subsubsection{Residential Open Building Lagging Behind}

In that sense residential Open Building is only doing what already is familiar in other building types. The reasons for this lag are several. Commercial residential projects, in contrast to the commercial office building, usually operate in a sellers market which leaves no incentive for innovation because the product is sure to sell anyway. Non-profit housing organizations have not much incentive either to delegate design responsibility to the occupant. Moreover, the fitout of residential units is more complex compared to retail or office space. Kitchen and bathroom equipment in combination with general heating, ventilation, communication and power supply systems must be integrated in a small volume. Finally, we can note that in the practice of the office building and the shopping mall, the separation of base building and fit-out remains very much a pragmatic affair without much study or professional debate. There is reason to think that here too, performance is much lower than potential would allow.

\subsection{A Direct Relationship}

The examples given may illustrate that Open Building projects, both residential and commercial, combine two aspects. One has to do with hardware and entails the distinction of 
separate configurations - base-building and fit-out - and the potential for their systematization and industrial production. The other is the distribution of design control: where traditionally the large project was under unified design control, now part of it is under control of a large number of individual occupants. Open Building sees the distribution of design control as a condition for systematization in the building industry: A clear base-building typology enhances systemic development. Most importantly, it opens a market for fit-out systems serving individual households, retail units and business entities. Conversely, further systematization of fit-out makes individual adaptation easier and therefore is an incentive for further distribution of design control. Open Building's strength, ultimately, is that it brings industrial construction in contact with the individual inhabitant in a direct relationship without mediation.

\subsection{Infrastructure and Consumer Product}

This direct relationship is characteristic for contemporary industrialized society. The cell phone, television, the computer, our clothes and most other things we use daily are the product of it. The most prominent example is the automobile. Here too, a complex product is directly available to the user and its systematized production is now capable of making each car customized on demand. Surely, the lack of user control where residential construction is concerned is out of tune with contemporary society's values.

More to the point, an industry serving the user often demands an infrastructure: The manufacturing of cars requires a network of roads. Similarly, use of the mobile phone demands many thin masts and satellites orbiting the earth. By the same token, when we think of the individual dwelling as an industrial product under control of the user, a shared infrastructure must provide the space for that relationship to be productive in. With the free standing house this infrastructure may be the land on which we build with the roads that make it accessible and the utility systems that serve it. In higher density conditions it must be the base-building.

\section{THE SYSTEMATIZATION OF BUILDING}

The systematization of building is accelerating. It is generally agreed that in the past two or three decades value added to the building by the manufacturer has been steadily increasing while value added by the general contractor has decreased proportionally. Designing a building has become an orchestration of available systems. Windows, doors, exterior wall panels and entire curtain walls, interior partitioning, floor slabs, elevators and stairs, balconies and banisters etc. etc. are all offered in manufacturer's catalogues. Not to forget the various utility systems bringing power, gas, water and information in our homes and getting waste out.

Do-it-yourself outlets show us how many of these systems already have entered in direct relation with the lay person. In the North American continent almost the entire free standing house can be self built. In Europe, do-it-yourself retail provides all sub-systems needed for apartment fitout. Initially, systematization was not intended to serve the self-help user. The employment of unskilled labor on site pushed the production of intricate parts to the factory. But what makes it easy for on-site labor, makes it easy for the user, and a new retail industry was born.

The most advanced example of environmental hardware as a consumer product is found in the kitchen systems that have come to permeate residential environment, particularly in Europe and Japan. You can select your kitchen parts in IKEA outlets and put them together all by yourself. Those reluctant or unable to do so, find dealers who are happy to assist their clients in designing their own, and send a specialized crew to install the chosen combination. Not so long ago, the kitchen used to be an integral part of the building. Today, in the Netherlands, no developer will any longer install kitchens in houses put up for sale: he expects the buyer to order his kitchen directly from a dealer.

\subsection{An Open System}

The Kitchen system itself is an Open system because it is a composite of autonomous subsystems. In addition to cabinets it also includes a desk top with a sink, a cooking range, an oven, a dishwasher, a refrigerator and a freezer. It may include a hot water boiler and an exhaust ventilator. Further more we find in it lighting fixtures and outlets for electric power. The cooking range may be fed by a gas line and the sink needs to be connected to hot and cold water as well as a drainage system. The kitchen system designer may have designed the sub-system of cabinets, but all other parts have been designed 
and produced by other manufacturers who are not beholden to the kitchen system.

This openness has the advantage that a better subsystem can easily replace an older version, keeping the composite offering up to date. At the same time, the manufacturer and designer of, say, a faucet or dishwasher can compete for incorporation of their product in a wide range of kitchen systems.

\subsection{Coordination of Parts}

The coordination of so many products into a larger composite system is based on the simple principle that standardization must only deal with interface conditions. Where products of two producers meet, conventions of details and dimensions must be established. Beyond that, each designer is free to do his or her own.

This successful openness was not the result of top down regulation or a single invention, but the slow gain of practice. Over the years, the concept of a kitchen system became familiar to users and producers alike. Conventions of use and assembly became sufficiently stable for industry to formalize them. Social habit and consensus produced the sophisticated coordination we now take for granted.

\subsection{Social Conventions}

This is a lesson worth remembering: The systematization in building occurs when habits are formed and a way of working becomes generally accepted. Once a generally accepted routine appears, the door to industrial production of dedicated systems is open. It is often thought that industrialization shapes society, and of course that is true as well, but certainly in building practice, that is only part of the story. In the last century, countless inventions and proposals for building systems of all kinds have come to grief because they were not accepted by everyday practice. They demanded new ways of working but could not compete with already settled habits and customs. What eventually became successfully produced by the manufacturer was more often than not already done in the field, and industry seized the opportunity to do it better and more efficiently.

Today, after the upheavals and revolutions of Modernism, our ways of building and living increasingly show stable conventional patterns, often on a global scale. These patterns breed systematization and this, in turn, makes true industrial production possible. With as result the increasing industrialization we have noted.
When I speak of conventions and habits I do not mean only professional ways of working, but also the patterns of living of the inhabitant. It is in the latter that industry can establish the direct relationship with the user that already has been so successful in many other aspects of our lives. Thus we can distinguish two modes of industrialization in environmental production. The one which is most familiar serves the actual process of building. Here industry connects to the professional world to maintain a dialectical relationship with ongoing ways of design and management and on-site construction. The other, which is new, serves the user-inhabitant directly via dealers and specialized fit-out installers. Here, part of what used to be real estate becomes a consumer product, following a model already known in other aspects of daily life but not, so far, in environmental production.

The kitchen system is the most advanced example of that new trend. Bathroom systems may well be next. Eventually they will be combined in comprehensive fit-out systems as advocated by Open Building.

\section{RE-DISTRIBUTION OF DESIGN CONTROL}

If fit-out systems would indeed be available like cars are today, we would have a new consumer market that rivals that of private motor vehicles. Before we rejoice in this seductive vision we must ask ourselves how the base buildings will come about that must hold the countless fit-out units industry will make available to the individual user. One answer is that the product will trigger the infrastructure. When the car first appeared, the freeways were not there: they came later. As with the kitchen system, fit-out systems will eventually establish themselves and base-buildings will result.

This answer is attractive to those of us who like to design and invent systems and believe in the potential of industrial production. But others will point out that we inherited from Modernism a centralized design decision process that is well established among professionals who see no merit in changing it. In conventional residential building practice, the first thing to be designed is the floor plan of the unit. Once that is known, all parties can get to work. The structural engineer can design the load bearing structure, the consultants for utility systems can design the distribution of all manner of conduits through the building. Bankers can assess loans, developers can calculate expenses and profits, bureaucrats can give 
permits. When we design a base building there is no floor plan. A new methodology of design and decision making is in order. But professionals, like normal people, prefer not to change their ways of working.

\subsection{Systems design and Instance Design}

Re-distribution of design control is part and parcel of industrial systematization. To make the kitchen system work two kinds of design are in order. There is the design of the system as such, and there is the design of the many instances of it. The two together make the kitchens appear in our homes. Hence we find a distribution of design control. Details, dimensions of parts, connections of parts, materials, textures, and colors of the parts, all must be decided by the system designer. His design decisions are general: they determine what all instances that can be made by combining the parts will share. In contrast, the design decisions pertaining to a single instance are unique because the user and the location are unique. This distribution of design responsibility allows industry to serve countless individual users.

\subsection{A Matter of Policy}

It is good to bear in mind that the examples of Open Building that I showed you, as well as all others that are on record, have been implemented in a state-of-the-art technology, without the benefit of any dedicated fit-out systems offered by the industry. In other words, these first experimental projects were demonstrations of redistribution of design control first of all. They illustrate the power of the new game to be played. They also made clear how much easier it would be if dedicated fit-out systems would be available. It could not be otherwise: we have just seen how successful systematization follows already settled practice. If that is true, the issue of re-distribution of design in practice must be addressed head on to open the way for truly industrial fit-out systems.

Frank Bijdendijk, who runs one of the largest nonprofit housing corporations in the Netherlands will tell you he does not think Open Building is a technical problem but a matter of re-distribution of responsibility first of all. He invested years of study and development to establish a policy where his tenants would be offered ownership - and hence full responsibility - for everything behind their front door. The housing corporation would be responsible for the building as a shared property of all inhabitants. Banks agreed to give mortgages to these new fit-out owners, the costs of which would be tax deductible like they are for owners of private homes.

Implemented on a national scale in the Netherlands, where the majority of households rent their homes, this would make a very large part of existing housing stock eligible for unit-byunit renewal and renovation, creating a tremendous incentive for industrial innovation.

However, Dutch tax law was overhauled recently and no longer allows deduction of mortgage costs on fit-out ownership while maintaining the privilege for 'real' home owners. We may assume this sad case of discrimination was not the result of ill will, but of ignorance. Economists, lawyers, politicians, bankers, industrialists and other policy makers need to know what Open Building policy is about. In a few countries governments have begun to subscribe to this approach and support research and experimentation. Japan and Finland are among them. The Netherlands is one too, as you will hear from another speaker on this conference. But the need for re-distribution of design responsibility is not yet generally understood. Issues of Open Building policy are not yet topics of debate and study among professionals and policy makers.

But then again, as those who believe in the power of invention will say, once the car was known, the roads got built.

\section{REFERENCES}

[NEXT21], see: GA JAPAN Environmental Design, Jan-Feb 1994, and: DOMUS no.819, October 1999.

[v.d.Werf] Frans van der Werf and Hubert Paul Froyen; Molenvliet-Wilgendonk: Experimental Housing Project. In: Beyond the Modern Movement, The Harvard Architecture Review, Volume 1, Spring 1980.

[Kendall] Stephen Kendall and Jonathan Teicher, Residential Open Building, E \& FN Spon, London and New York, 2000. 